\title{
In Vitro Immersion Behavior of Cold Sprayed Hydroxyapatite/Titanium Composite Coatings
}

\author{
Lin Lu',2, Xuan Zhou ${ }^{3 *}$, P. Mohanty ${ }^{2}$ \\ ${ }^{1}$ School of Materials Science and Engineering, Beijing Institute of Technology, Beijing, China \\ ${ }^{2}$ Department of Mechanical Engineering, University of Michigan, Dearborn, USA \\ ${ }^{3}$ Department of Electrical and Computer Engineering, Kettering University, Flint, USA \\ Email: xzhou@kettering.edu
}

Received November 2013

\begin{abstract}
In previous study, dense and homogenous 20wt\% HAP/Ti composite coatings were successfully deposited on Ti substrates by cold gas dynamic spray technique. The results revealed that the phase composition of the HAP in the deposit is identical to that of the precursor powder and the bonding strength of the deposit is comparable/better to that of the plasma sprayed HAP. A relatively higher corrosion current of HAP/Ti composite than that of pure Ti coating in simulated body fluid indicates a good bioactivity for composite coating. In the present study, in vitro immersion test is carried out for various period of time and the formation of apatite layer on surface of composite coating proves the good bioactivity of the composite coating further. The cold sprayed HAP/Ti composite can be anticipated to be a promising load-bearing implant material for biomedical applications.
\end{abstract}

\section{Keywords}

Cold Spray; Hydroxyapatite (HAP)/Titanium Composite; In Vitro Immersion; Corrosion

\section{Introduction}

Hydroxyapatite [HAP, $\mathrm{Ca}_{10}\left(\mathrm{PO}_{4}\right)_{6}(\mathrm{OH})_{2}$ ] has been widely used as dental and orthopedic implant materials because it chemically connects the implant with the bone due to its chemical and crystallographic similarity with bone minerals [1]-[3]. It has been proved that the existence of HAP coating not only induces the bone growth between implant material and bone but also improves the bonding strength of the implants to the bone [4]. However, the poor mechanical properties such as low fracture toughness and low modulus of elasticity of HAP hindered its application as a load bearing implant [5]. For this reason, HAP coatings have been deposited on mechanically strong and biocompatible metallic materials such as titanium and its alloys [6]-[9]. This approach combines the good bioactivity of HAP and mechanical advantage of metallic materials. Nevertheless, the bond-

*Corresponding author.

How to cite this paper: Lu, L., Zhou, X. and Mohanty, P. (2014) In Vitro Immersion Behavior of Cold Sprayed Hydroxyapatite/Titanium Composite Coatings. Journal of Biosciences and Medicines, 2, 10-16. 
ing strength of HAP coating, and its long term stability after implantation are still questionable. An effective approach to solve this problem is to form a composite coating by reinforcing the HAP coating with a mechanically strong second phase, such as Ti [5], Ti6Al4V [10] and carbon nano-tube [11] et al.

Cold gas dynamic spray technique has been applied to deposit biocompatible HAP composite coatings. And some tentative but meaningful results were obtained. For example, Taylor et al. utilized cold spray technique to deposit HAP/Ti composite coatings on aluminum substrates and studied the effect of percent of HAP on the thickness, microstructure and bonding strength of deposited coatings [12]. Maev et al. deposited HAP/phosphate glass composite coatings by cold spray approach and studied the effect of heat treatment on the crystallinity of deposited coatings [13]. However, due to the low deforming capability of HAP, reports of successful fabrication of composite coatings consisting of HAP and Ti by cold spray technique are few and to the best of our knowledge, the study of in vitro immersion behavior of cold sprayed hydroxyapatite/titanium composite coatings is still not available in open literature.

In this study, the in vitro immersion behavior of composite coatings as well as pure Ti coatings was investigated in simulated body fluid (SBF) solution and corrosion behavior was characterized by cyclic voltammetry tests.

\section{Experimental Details}

\subsection{Electrochemical Corrosion Studies}

The electrochemical measurements were carried out using a flat three-electrode cell (K0235 Flat Cell, Princeton Applied Research), with the samples acting as the working electrode, $\mathrm{Ag} / \mathrm{AgCl}$ electrode as the reference electrode and a platinum grid as the counter electrode. The specimen area exposed to the electrolyte solution is 1 $\mathrm{cm}^{2}$. The simulated body fluid (SBF) used in this study is Hanks' balanced salt solution purchased from Media tech Inc. The composition of Hanks' balanced salt solution can be found in previous study [2].

Electrochemical corrosion properties were determined by using a Solartron SI 1287 potentiostat. Prior to each measurement, all samples (as-received Ti coatings and HAP/Ti composite coatings) were polished progressively until a mirror finish surface was achieved. In order to avoid the possible oxidation of samples, the electrochemical tests were commenced immediately after immersion of the samples in Hanks' solution. The cyclic voltammetry curves were obtained in the potential range of $-1 \mathrm{~V}$ to $3.5 \mathrm{~V}$ with the scan rate of $1 \mathrm{mV} / \mathrm{s}$. All the experiments were carried out at least three times under ambient temperature.

\subsection{Immersion Test of Deposited Coatings in Hanks' Solution}

The coated specimens were immersed in vials with $50 \mathrm{ml}$ of Hanks' solution. The experiment was performed at $37^{\circ} \mathrm{C}$ and the vials were sealed to remain sterile. After certain periods of time, the specimens were removed from Hanks' solution, washed with distilled water and dried at room temperature. Then, the morphological and elemental analysis of the coatings was studies by SEM/EDX (HITACHI S-2600N).

\section{Results and Discussion}

\subsection{Electrochemical Corrosion Behavior of 20wt\% HAP/Ti Composite Coatings}

Figure 1 shows the cyclic voltammograms for cold sprayed Ti and 20wt\% HAP/Ti composite coatings in Hanks' solution. It is evident that for both starting and final corrosion potential, Ti coating has relatively higher corrosion potential than HAP/Ti composite coating. Both samples showed obvious passivation zone in a similar potential range of $-0.3 \mathrm{~V}$ to $1.6 \mathrm{~V}$, while the composite coating has the higher passivation current. From potential above $1.6 \mathrm{~V}$, the anodic current density of Ti coating increased at a faster rate, indicating $\mathrm{TiO}_{2}$ passive layer breakdown [14] and at a potential around $2.2 \mathrm{~V}$, a current oscillation is observed, which typifies a pitting nucleation and re-passivation process. It is noted that the existing pores on the coating surface may extend as pits into the sample. Basically, the cold sprayed coatings are coatings consisted of porous top layer and dense bottom layer [15]. For the cold sprayed 20wt\% HAP/Ti composite coating, no obvious pitting corrosion was observed, which indicated a relatively dense and homogenous coating obtained.

\subsection{Immersion Behavior of 20wt\% HAP/Ti Composite Coatings in Hanks' Solution}

The surface morphologies of 20wt\% HAP/Ti composite coatings after immersion in Hanks' solution for various 
periods are shown in Figure 2. It can be seen that after four days of immersion, the top surface of HAP part coating appeared dissolved during immersion; some spherical particles have grown on the top surface of Ti part coating (Figure 2(a) inset picture). The EDX analysis confirmed that Ca, P element contained in these particles. More spherical particles precipitate and the size of the initially precipitated spherical particles increases as immersion duration increases. After one week of immersion, the composite coating surface is found completely covered by a dune like layer with spherical particles embedded inside. The EDX analysis indicates that the layer is apatite layer composed of Ca, P, and O (Figure 3). It is also found that some microcracks formed in the apatite layer. The occurance of these microcracks is beleived caused by drying shringkage [16] or resulted from diffusion and reaction between coating and Hanks'solution [9]. When the immersion time was increased to two weeks, the layer becomes dense and the granular particles in the apatite layer grows further. The EDX analysis also shows the increase of the intensity of P, Ca elements after two weeks of immersion compared to that of one week of immersion (Figure 3), which indicates the newly formed apatite layer becomes thicker with elongation of the immersion duration. After three weeks, many granular particles nucleate and precipitate in the initially formed apatite layer, which indicates the continuous growing ability of apatite layer (Figure 2(d)).

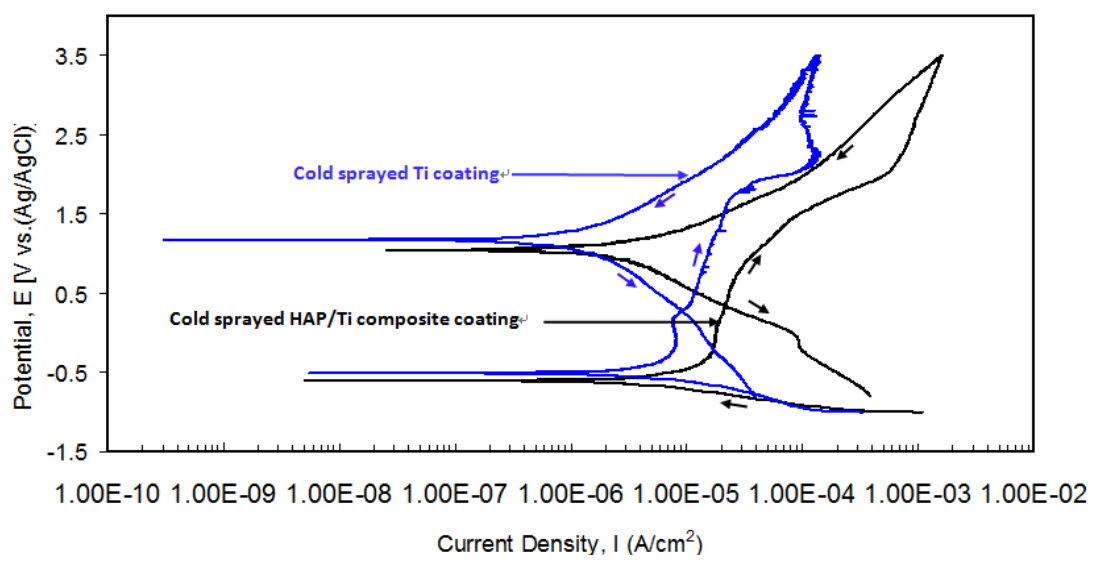

Figure 1. Cyclic voltammogram for cold sprayed Ti and 20wt $\%$ HAP/Ti composite coatings.

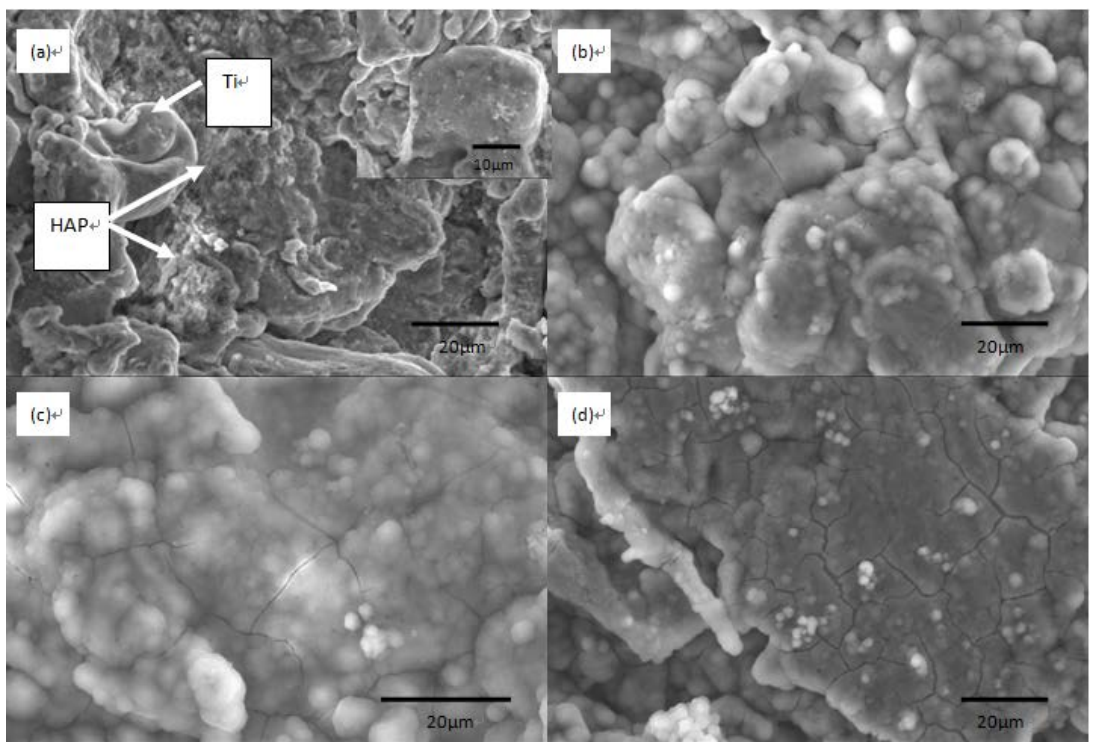

Figure 2. Surface morphologies of 20wt\%HAP/Ti composite coatings after immersing in Hanks' solution for various periods of time: (a) four days (inset is high magnification image showing the spherical apatite particles formed on surface of Ti part coating); (b) one week; (c) two weeks; (d) three weeks. 


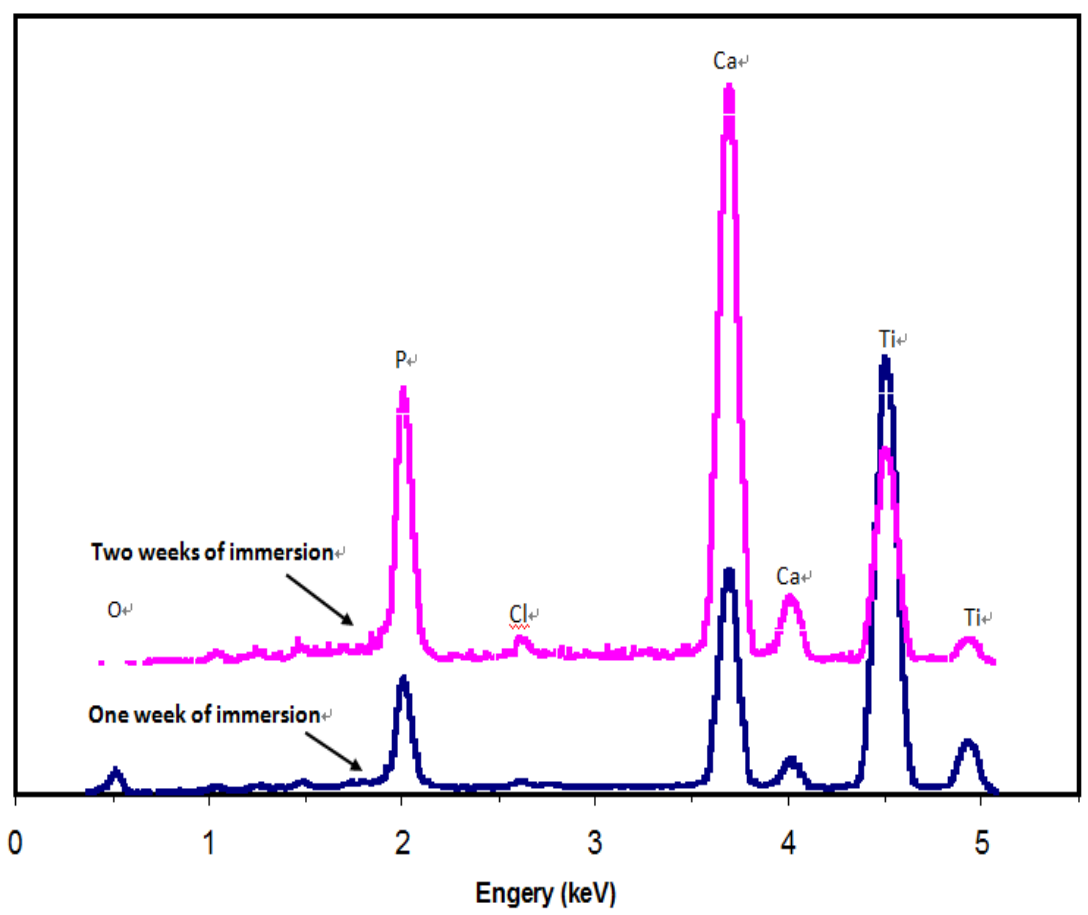

Figure 3. EDX spectra of the 20wt $\%$ HAP/Ti composite coating after one and two weeks immersion.

The immersion behavior of cold sprayed pure Ti coating in Hanks' solution is also investigated for comparing purpose and the results are presented in Figure 4. After 5 days of immersion (Figure 4(a)), a crystalline structure is observed precipitated on the surface of Ti coating. Detailed examination ((Figure 4(a) inset picture) revealed its dendritic shape. The corresponding EDX result shown in Figure 5 confirmed the presence of elements such as $\mathrm{Ca}, \mathrm{P}$ and $\mathrm{O}$. With immersion time prolonged to 12 days, a dense layer with spherical particles inside formed on some Ti particles surface. Some microcracks are also observed on the newly formed layer. However, unlike the EDX results for composite coating, elements such as $\mathrm{Na}, \mathrm{Mg}$ are also detected besides $\mathrm{Ca}, \mathrm{P}$ and $\mathrm{O}$ (Figure 5). It can be seen from Figure 4(c) that after immersion of three weeks, the newly formed layer became denser and more crystalline structures precipitate. However, compared with apatite layer formed on composite coating, this newly formed layer on pure Ti coating shows different morphology: more like precipitated crystalline structure with dendritic shape not dune like apatite layer. Figure 4(d) shows the low magnification view of Ti surface after immersion of three weeks. As it is shown, the newly formed layer occupies part of Ti surface. This result indicates that some parts of the pure Ti coating are more active than the others.

The good bioactivity of cold sprayed HAP/Ti composite coatings is confirmed by the nucleation and growth of a bone-like apatite layer in Hanks' solution. Only 20wt\% HAP contained in our coatings is sufficient to induce the formation of apatite layer in Hanks' solution and the addition of Ti does not distinctly affect the formation of apatite layer. A query on highly crystalline HAP coating deposited by cold spraying may be raised, since highly crystalline HAP coating is difficult to absorb in SBF [17] and an amorphous coating is more beneficial for early stage of bone in growth [18]. Our results indicated that the nucleation of apatite particles on Ti part coating (Figure 2(a) inset picture) may stimulate the nucleation of apatite particles on highly crystalline HAP part coating. Highly crystalline HAP promotes the growth of these nucleated apatite particles to form an apatite layer to cover the entire surface of composite coating. One may argue that the naturally formed $\mathrm{TiO}_{2}$ is not bioactive enough to induce Ca-P precipitation [19]. For cold sprayed coating, due to the porous nature of top layer, $\mathrm{TiO}_{2}$ thin films with porous structure are expected to form on the top surface of coating in Hanks' solution. And the bioactivity of $\mathrm{TiO}_{2}$ with porous structure has been proved by Li et al., which could lead to Ca-P deposition [20]. The correlations and effects between formation of apatite layer on HAP and Ti part coating deserved more investigations. In addition, for cold sprayed pure Ti coating, although a newly formed layer containing elements of $\mathrm{Ca}, \mathrm{P}$ and $\mathrm{O}$ was observed after immersion of three weeks, morphology different with traditional dune like 


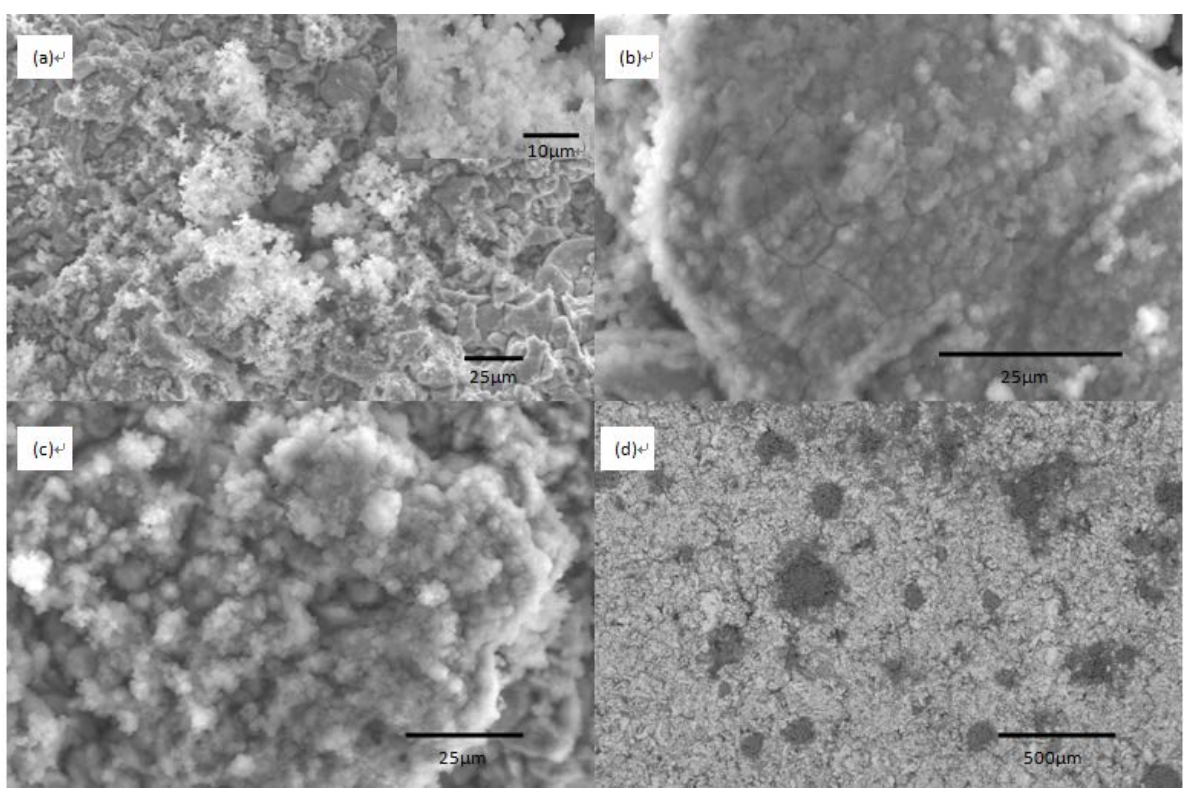

Figure 4. Surface morphologies of pure Ti coatings after immersing in Hanks' solution for various periods of time: (a) five days (inset is high magnification image showing the crystalline structure precipitate); (b) twelve days; (c) three weeks; (d) three weeks (low magnification view).

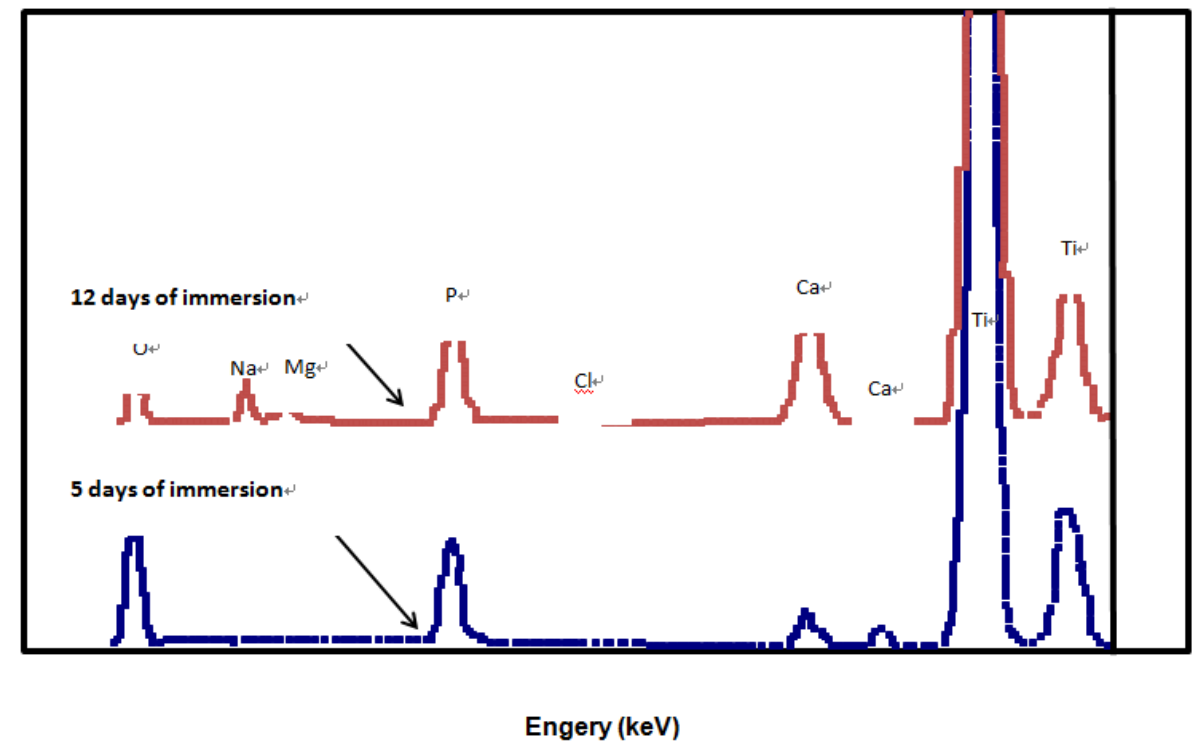

Figure 5. EDX spectra of the pure Ti coating after 5 days and 12 days of immersion.

apatite layer was obtained. Whether osteoblasts can proliferate on this newly formed layer on pure Ti coating and let the bone matrix integrates into it needs more studies in vivo experiment. The above mentioned questions are under investigation and will be discussed in the following paper.

Commercially, HAP powders (\$395/kg, Plasma Biotal Limitted) are much more expensive than Ti powders (\$85/kg, Accushape, Inc). Compared to plasma sprayed 100wt\% HAP coating and HAP/Ti composite coating with 80 and 40wt\% HAP [21], only 20wt\% HAP used in our cold spraying method could reduce the cost greatly.

\section{Conclusion}

In this study, 20wt\% HAP/Ti composite coatings have been successfully deposited by cold spray technique, 
without compromising the phase constituents of HAP. A relatively higher corrosion current of composite coating than that of Ti coating indicates a good bioactivity of composite coating, which is consistent with the results of in vitro immersion test. After one week of immersion, a dune like apatite layer was observed on the surface of 20wt\%HAP/Ti composite coating and the apatite layer became denser and thicker with the increase of immersion duration. The present results indicate the potential applications of cold sprayed HAP/Ti composite coatings under load-bearing conditions as well as potential economical effect since only $20 \mathrm{wt} \%$ HAP used in the coatings.

\section{Acknowledgements}

The authors gratefully acknowledge financial assistance from the Naval Health Science Laboratory, under contract No: W911QY-09-C-0011. The authors would like to thank late Mr. Abhinav Chaudhari, Dr. J. Karthikeyan (ASB Industries for facilitating the initial experiments), Dr. Yaping Wang(School of Science, Xi'an Jiaotong University, Xi’an, China) for helpful discussions.

\section{References}

[1] Morks, M.F., Fahim, N.F., Kobayashi, A. (2008) Structure, Mechanical Performance and Electrochemical Characterization of Plasma Sprayed $\mathrm{SiO}_{2} /$ Ti-Reinforced Hydroxyapatite Biomedical Coatings. Applied Surface Science, 255, 3426-3433. http://dx.doi.org/10.1016/j.apsusc.2008.09.088

[2] Zhou, X. and Mohanty, P. (2012) Electrochemical Behavior of Cold Sprayed Hydroxyapatite/Titanium Composite in Hanks' Solution. Electrochimica Acta, 65, 134. http://dx.doi.org/10.1016/j.electacta.2012.01.018

[3] Ning, C.Q., Zhou, Y. (2002) In Vitro Bioactivity of a Biocomposite Fabricated from HA and Tipowders by Powder Metallurgy Method. Biomaterials, 23, 2909-2915. http://dx.doi.org/10.1016/S0142-9612(01)00419-7

[4] Lima, R.S., Khor, K.A., Li, H., Cheang, P. and Marple, B.R. (2005) HVOF Spraying of Nanostructured Hydroxyapatite Forbiomedical Applications. Materials Science and Engineering, 396, 181-187. http://dx.doi.org/10.1016/j.msea.2005.01.037

[5] Zhou, X., Siman, R., Lu, L. and Mohanty, P. (2012) Argon Atmospheric Plasma Sprayed Hydroxyapatite/Ti Composite Coating for Biomedical Applications. Journal of Surface and Coating Technology, 207, 343. http://dx.doi.org/10.1016/j.surfcoat.2012.07.009

[6] Metikos-Hukovic, M., Tkalcec, E., Kwokal, A. and Piljac, J. (2003) An in Vitro Study of Ti and Ti-Alloys Coated with Sol-Gel Derived Hydroxyapatite Coatings. Surface and Coatings Technology, 165, 40-50. http://dx.doi.org/10.1016/S0257-8972(02)00732-6

[7] Tsui, Y.C., Doyle, C., Clyne, T.W. (1998) Plasma Sprayed Hydroxyapatite Coatings on Titanium substrates Part 2: Optimisation of Coating Properties. Biomaterials, 19, 2031-2043. http://dx.doi.org/10.1016/S0142-9612(98)00104-5

[8] Kweh, S.W.K., Khor, K.A. and Cheang, P. (2000) Plasma-Sprayed Hydroxyapatite (HA) Coatings with Flame-Spheroidized Feedstock: Microstructureand Mechanical Properties. Biomaterials, 21, 1223-1234. http://dx.doi.org/10.1016/S0142-9612(99)00275-6

[9] Kweh, S.W.K., Khor, K.A. and Cheang, P. (2002) An in Vitro Investigation of Plasma Sprayed Hydroxyapatite (HA) Coatings Produced with Flame-Spheroidized Feedstock. Biomaterials, 23,775-785. http://dx.doi.org/10.1016/S0142-9612(01)00183-1

[10] Gu, Y.W., Khor, K.A. and Cheang, P. (2003) In Vitro Studies of Plasma-Sprayed Hydroxyapatite/Ti-6Al-4VCOM POSITE Coatings in Simulated Body Fluid (SBF). Biomaterials, 24, 1603-1611. http://dx.doi.org/10.1016/S0142-9612(02)00573-2

[11] Balani, K., Anderson, R., Laha, T., Andara, M., Tercero, J., Crumpler, E. and Agarwal, A. (2007) Plasma-Sprayed Carbon Nanotube Reinforced Hydroxyapatite Coatingsand Their Interaction with Human Osteoblasts in Vitro. Biomaterials, 28, 618-624. http://dx.doi.org/10.1016/j.biomaterials.2006.09.013

[12] Taylor, K., Jodoin, B. and Karov, J. (2006) Utilization of Composite Powders to Apply Ceramic Coatings in Cold Spray. 5th International Surface Engineering Congress, Washington State Convention Center, Seattle, Washington, 15-17 May 2006, 124.

[13] Maev, R.Gr., Weinert, H., Maeva, E., Leshchynsky, V., (2008) Low Pressure Gas Dynamic Spray of Hydroxyapatite Composite Coatings. 17th International Scientific and Techanical Conference, Poland, 22-24 September 2008.

[14] Hsu, R.W.W., Yang, C.C. and Huang, C.-A. (2004) Electrochemical Corrosion Properties of Ti-6Al-4V Implantalloy in the Biological Environment. Materials Science and Engineering A, 380, 100-109. http://dx.doi.org/10.1016/j.msea.2004.03.069 
[15] Li, C.-J. and Li, W.-Y. (2003) Deposition Characteristics of Titanium Coating in Cold Spraying. Surface and Coatings Technology, 167, 278-283. http://dx.doi.org/10.1016/S0257-8972(02)00919-2

[16] Gu, Y.W., Khor, K.A., Pan, D., Cheang, P. (2004) Activity of Plasma Sprayed Yttria Stabilized Zirconia Reinforcedhydroxyapatite/Ti-6Al-4V Composite Coatings in Simulatedbody Fluid. Biomaterials, 25, 3177-3185. http://dx.doi.org/10.1016/j.biomaterials.2003.09.101

[17] Gross, K.A., Berdt, C.C. (1994) In Vitro Testing of Plasma-Sprayed Hydroxyapatite Coatings. Journal of Materials Science: Materials in Medicine, 5, 219-224. http://dx.doi.org/10.1007/BF00121092

[18] Maxian, S.H., Zawadsky, J.P. and Dunn, M.G. (1993) In Vitro Evaluation of Amorphous Calciumphosphate and Poorly Crysiallized Hydroxyapatitecoatings on Titanium Implants. Journal of Biomedical Materials Research, 27, 111-117. http://dx.doi.org/10.1002/jbm.820270114

[19] Kokubo, T., Miyaji, F., Kim, H.-M. andT. Nakamura (1996) Spontaneous Formation of Bonelike Apatite Layer on Chemically Treated Titanium Metals. Journal of the American Ceramic Society, 79, 1127-1129. http://dx.doi.org/10.1111/j.1151-2916.1996.tb08561.x

[20] Li, P. (1993) Ph.D. Thesis, Leiden University, The Netherlands.

[21] Zheng, X.B., Huang, M.H. and Ding, C.X. (2000) Bond Strength of Plasma-Sprayed Hydroxyapatite/Ticomposite Coatings. Biomaterials, 21, 841-849. http://dx.doi.org/10.1016/S0142-9612(99)00255-0 